\title{
CARACTERÍSTICAS DO PELAME DE CABRAS SAANEN E PARDO ALPINA CRIADAS EM AMBIENTE TROPICAL
}

\author{
HAIR COAT CHARACTERISTICS OF SAANEN AND OBERHASLI GOATS IN TROPICAL \\ ENVIRONMENTS
}

\author{
Aiura, A.L.O. ${ }^{1}$, Aiura, F.S. ${ }^{1}$ e Silva, R.G. ${ }^{3}$
}

\begin{abstract}
1'Departamento de Ciências Agrárias. UNIMONTES. Janaúba, MG. Brasil. aurilopes@yahoo.com.br; felipe.aiura@unimontes.br

${ }^{2}$ Departamento de Zootecnia. Faculdade de Ciências Agrárias e Veterinárias. UNESP. Jaboticabal, SP. Brasil.robertogs@terra.com.br
\end{abstract}

Palavras chave adicionais

Adaptação. Caprinos. Trocas térmicas.

\section{RESUMO}

Realizou-se um estudo das seguintes características morfológicas do pelame: espessura da capa $(E)$, comprimentos médios dos pêlos (C), número de pêlos por área $(\mathrm{N})$, ângulo de inclinação dos pêlos em relação à superfície $(A)$ e diâmetro médio dos pêlos (D) em 532 cabras das raças Saanen e Pardo Alpina criadas em ambiente tropical As médias e erros-padrões dessas características foram: $E=6,04 \pm 0,08 \mathrm{~mm} ; C=33,17 \pm 0,24$ mm; $\mathrm{N}=191,50 \pm 4,67$ pêlos. $\mathrm{cm}^{-2} ; A=10,67 \pm 0,15$ graus e $D=0,203 \pm 0,0013 \mathrm{~mm}$.

\section{SUMMARY}

The aim of the present work was to study the morphological characteristics of the hair coat, coat thickness $(E)$, hair length $(C)$, number of hair by unit area $(\mathrm{N})$, hair angle to skin $(\mathrm{A})$ and hair diameter (D) of Saanen and Oberhasli goats, measured under the conditions of tropical environment. The observed averages of these traits were: $E=6.04 \pm 0.08 \mathrm{~mm} ; C=33.17 \pm 0.24 \mathrm{~mm}$; $\mathrm{N}=191.50 \pm 4.67$ hairs. $\mathrm{cm}^{-2} ; A=$ the $10.67 \pm 0.15$ degrees; $D=0.203 \pm 0.0013 \mathrm{~mm}$.

\section{INTRODUÇÃO}

As características morfológicas do pelame são importantes na regulação do calor corporal, influenciando diretamente as trocas de calor entre os animais e o

Recibido: 22-1-09. Aceptado: 5-3-09.

\section{AdDitiOnAL KEYWORDS}

Adaptation. Goats. Heat load.

ambiente, sendo assim indicadores de adaptação dos animais ao seu habitat (Cena e Monteith, 1975abc).

Em ambiente tropical os bovinos que possuem um pelame de cor clara e pêlos curtos, grossos e bem assentados, sob uma epiderme altamente pigmentada, suportam melhor as condições desse ambiente (Silva et al., 2001; Maia et al., 2003, 2005).

Existem poucas informações sobre características morfológicas do pelame em caprinos de origem européia, que vêm sendo utilizados para produção e melhoramento do rebanho brasileiro de variedades naturalizadas. O objetivo foi estudar as características morfológicas do pelame em caprinos das raças Saanen e Pardo Alpina mantidos em uma região tropical.

\section{MATERIALE MÉTODOS}

Foram realizadas medições em 532 animais das raças Saanen e Pardo Alpina em dois rebanhos, um em Viçosa, MG, Brasil (2045'45" Sul, 4252'04" Oeste, $657 \mathrm{~m}$ altitude), com clima do tipo Cwb de Köppen e outro em São José do Rio Preto, SP, Brasil (2049'11" Sul, 49²2'46" Oeste, 489 m altitude), de tipo climático Aw.

Arch. Zootec. 59 (228): 609-612. 2010. 
As características morfológicas do pelame foram: espessura da capa (E, $\mathrm{mm})$, comprimento médio dos pêlos (C, mm), número de pêlos por unidade de área $(\mathrm{N}$, pêlos. $\mathrm{cm}^{-2}$ ), ângulo de inclinação dos pêlos (A, graus), e diâmetro médio dos pêlos (D, $\mathrm{mm})$.

Em cada animal, na região centro-lateral do tronco, $18 \mathrm{~cm}$ abaixo da coluna vertebral, foi medida a espessura da capa, com auxilio de uma régua milimetrada. Em seguida, retirada uma amostra de pêlos, por meio de um alicate de bico limado, com $18 \mathrm{~mm}^{2}$ de abertura, conforme Lee (1953).

A contagem do número de pêlos foi realizada, calculando-o por unidade de área. O comprimento médio dos pêlos foi determinado pela média aritmética dos dez maiores, medidos com paquímetro digital, conforme Udo (1978) e posteriormente o diâmetro médio, utilizando um micrômetro digital. O ângulo de inclinação dos pêlos em relação à superfície da epiderme foi obtido através da fórmula, $\mathrm{A}=\operatorname{arcsen}(\mathrm{E} / \mathrm{C})$, conforme Silva etal.(2001).

Mediu-se a cada hora as temperaturas do psicrômetro e globo negro (Tgn), além da velocidade do vento (Vv). Para a temperatura radiante média (Trm) e pressão parcial de vapor do ar $(\mathrm{P})$ foram usadas as fórmulas apresentadas por Silva (2000).

A análise de variância foi realizada pelo método de quadrados mínimos e o teste de Tukey $(p<0,05)$ para a comparação das médias, utilizando o programa SAS (1998).

O modelo geral para as características morfológicas foi:

\footnotetext{
$Y_{i j k}=\alpha+L_{i}+R_{j}+S_{i j}+b_{1}\left(E_{i j k}\right)+b_{2}\left(C_{i j k}\right)+b_{3}\left(N_{i j k}\right.$ $+b_{4}\left(D_{i j k}\right)+b_{5}\left(\operatorname{Trm}_{i j k}\right)+b_{6}\left(P_{i j k}\right)+b_{7}\left(I_{i j k}\right)+\varepsilon_{i j k l}$

Onde:

$Y_{i j k}$ são as médias da espessura da capa, comprimento médio dos pêlos, número de pêlos por unidade de área, ângulo de inclinação dos pêlos, diâmetro médio dos pêlos da k-ésima cabra, $L_{i}$ é o efeito fixo do i-ésimo local de coleta $(i=1,2)$; $R_{i}$ é o efeito fixo daj-ésimo raça $(j=1,2) ; S_{i j}$ é o efeito fixo da interação do i-ésimo local e j-ésima raça $(k=$
}

$1,2,3,4) ; b_{1}, b_{2}, b_{3}, b_{4}, b_{5}, b_{6}, b_{7}$ são os coeficientes de regressão sobre a espessura da capa, comprimento, número, e diâmetro dos pêlos, temperatura radiante média, pressão parcial de vapor e idade animal em anos, $\varepsilon_{i \mathrm{ik}}$ é o resíduo, incluindo o erro aleatório e a é o intercepto.

\section{RESULTADOSEDISCUSSÃO}

As médias das variáveis ambientais encontram-se na tabela I.

Através do resultado da análise de variância, observou-se efeito de local para as características espessura, densidade numérica e ângulo de inclinação no pelame dos animais (tabela II), o que pode ser atribuído as condições edafoclimáticas de cada localidade. As características morfológicas do pelame comprimento, número e diâmetro dos pêlos foram influenciadas pelas raças dos animais (tabela II). Ainda observou-se que as mesmas raças tiveram comportamentos diferentes em ambos locais (tabela III), quanto à espessura e o ângulo de inclinação, onde as médias apresentaram-se maiores em Viçosa.

De acordo com as características morfológicas do pelame (tabela II) os caprinos apresentaram pelame espesso, comprido, pouco denso, finos e bem assentados. Características que podem ser indicativo de maior adaptação ao ambiente tropical. Em estudo de tolerância ao calor com cabras da raça Sirohi, Acharya et al. (1995) observaram que os animais com pelame mais comprido tiveram melhor proteção ao ganho térmico da radiação solar.

Desse modo, as características morfológicas do pelame podem indicar a condição de aclimatização ou adaptação dos animais ao meio em que vivem. Uma maior espessura e comprimento dificultam a perda térmica do animal para o ambiente, o que nos leva a acreditar que seja o motivo dos animais de Viçosa apresentarem menor densidade de pêlos. Essa característica pode facilitar a movimentação do ar entre os pêlos, promovendo maiores trocas convectivas e 


\section{CARACTERÍSTICAS DO PELAME DE CABRAS EM AMBIENTE TROPICAL}

Tabela I. Médias, mínimas e máximas das variáveis ambientais por locais de coleta. (Environmental variable mean, minimum and maximum in the collection locations).

\begin{tabular}{lcccc}
\hline Variáveis & \multicolumn{2}{c}{ São José do Rio Preto } & \multicolumn{2}{c}{ Viçosa } \\
& Média & Mín-Máx & Média & Mín-Máx \\
\hline Ta $\left({ }^{\circ} \mathrm{C}\right)$ & 25,40 & $23,00-28,00$ & 27,41 & $22,00-32,00$ \\
$\operatorname{Trm}\left({ }^{\circ} \mathrm{K}\right)$ & 296,06 & $292,01-298,94$ & 299,22 & $267,50-326,72$ \\
$\operatorname{Tgn}\left({ }^{\circ} \mathrm{C}\right)$ & 24,40 & $21,50-27,00$ & 27,03 & $21,00-31,00$ \\
$\mathrm{~V} v\left(\mathrm{~m} / \mathrm{s}^{2}\right)$ & 0,35 & $0,20-0,50$ & 0,95 & $0,70-1,30$ \\
$\mathrm{P}(\mathrm{kPa})$ & 1,98 & $1,93-2,04$ & 1,82 & $1,67-2,21$ \\
\hline
\end{tabular}

$\mathrm{Ta}=$ temperatura do ar, $\mathrm{Trm}=$ temperatura radiante media, $\mathrm{Tgn}=$ temperatura do globo negro, $\mathrm{Vv}=$ velocidade do vento, $\mathrm{Ppv}=$ pressão parcial de vapor.

evaporativas. Por outro lado os animais de São José do Rio Preto apresentaram resultados em consonância com os indicados por Silva et al. (2001) e Maia et al. (2003) para ambiente tropical, com pêlos em maior número, menos espessos e bem assentados, sugerindo uma melhor proteção à radiação. Levando em conta que quanto maior for o número de fibras por unidade de área e quanto mais grossas forem essas fibras, maior será a quantidade de energia térmica conduzida através da capa (Silva, 2000).

A raça Saanen, caracterizada por pêlos e epiderme brancos, apresentou pelame mais denso que a raça Pardo Alpina (tabela II), possivelmente indicando a necessidade de maior proteção à radiação solar, ao mesmo tempo pêlos mais grossos e curtos, implicando na facilitação das trocas térmicas com o ambiente. Acharya et al. (1995), encontraram que cabras com pelagem branca tiveram menor estresse térmico do que as marrons e as pretas. Os pelames de coloração branca apresentam menores coeficientes de absorção, no entanto, deve-se levar em conta que a transmitância da radiação solar é maior que nos escuros (Silva et al., 2003; Maia et al., 2005).

A raça Pardo Alpina apresentou pelame menos denso (tabela II), podendo indicar

Tabela II. Médias estimadas por quadrado médio das características morfológicas do pelame de caprinos, de acordo com o local de coleta e raça. (Least squares means of the morphological traits of the hair coat in goats, according to the location, breed).

\begin{tabular}{lcccccc}
\hline Efeitos & $\mathrm{N}$ & $\mathrm{E}$ & $\mathrm{C}$ & $\mathrm{N}$ & $\mathrm{A}$ & $\mathrm{D}$ \\
\hline Média Geral & 532 & $6,04 \pm 0,08$ & $33,17 \pm 0,244$ & $191,50 \pm 4,67$ & $10,65 \pm 0,15$ & $0,203 \pm 0,0013$ \\
Local & & & & & & \\
$\quad$ Viçosa & 334 & $6,47^{\mathrm{a}}$ & $33,41^{\mathrm{a}}$ & $161^{\mathrm{b}}$ & $11,45^{\mathrm{a}}$ & $0,203^{\mathrm{a}}$ \\
$\quad$ S.J. Rio Preto & 198 & $5,32^{\mathrm{b}}$ & $32,66^{\mathrm{a}}$ & $243^{\mathrm{a}}$ & $9,28^{\mathrm{b}}$ & $0,207^{\mathrm{a}}$ \\
Raça & & & & & & \\
$\quad$ Saanen & 255 & $5,91^{\mathrm{a}}$ & $32,18^{\mathrm{b}}$ & $217^{\mathrm{a}}$ & $10,53^{\mathrm{a}}$ & $0,218^{\mathrm{a}}$ \\
$\quad$ Pardo Alpina & 277 & $5,87^{\mathrm{a}}$ & $33,88^{\mathrm{a}}$ & $187^{\mathrm{b}}$ & $10,23^{\mathrm{a}}$ & $0,191^{\mathrm{b}}$ \\
\hline
\end{tabular}

$E=$ Espessura do pelame; $C=$ Comprimento dos pêlos; $N=$ número de pêlos $/ \mathrm{cm}^{2} ; A=$ ângulo de inclinação dos pêlos; $D=$ diâmetro dos pêlos.

Médias seguidas da mesma letra não diferem estatisticamente pelo teste de Tukey $(p>0,05)$.

Archivos de zootecnia vol. 59, núm. 228, p. 611. 
Tabela III. Valores de espessura do pelame e ângulo de inclinação dos pêlos das raças Saanen e Pardo Alpina nos locais de coleta. (Coat thickness and hair angle to skin values in the Saanen and Oberhasli breed in collect location).

\begin{tabular}{lcc}
\hline Efeito & São José do Rio Preto & Viçosa \\
\hline Espessura & & \\
$\quad$ Saanen & $5,12^{\mathrm{Ba}}$ & $6,70^{\mathrm{Aa}}$ \\
$\quad$ Pardo Alpina & $5,51^{\mathrm{Ba}}$ & $6,23^{\mathrm{Aa}}$ \\
Angulo & & \\
$\quad$ Saanen & $9,02^{\mathrm{Ba}}$ & $12,04^{\mathrm{Aa}}$ \\
$\quad$ Pardo Alpina & $9,54^{\mathrm{Ba}}$ & $10,93^{\mathrm{Ab}}$ \\
\hline
\end{tabular}

Médias seguidas da mesma letra, minúsculo para coluna e maiúsculo para linha, para cada efeito, não diferem estatisticamente pelo teste de Tukey $(p>0,05)$.

maior facilidade das trocas por convecção e principalmente por evaporação, sendo que a mesma absorve mais calor devido aos seus pêlos coloridos e a pele escura. Contudo a coloração da epiderme e do pelame confere

\section{BIBLIOGRAFIA}

Acharya, R.M., Gupta, U.D., Sehgal, J.P. and Singh, M. 1995. Coat characteristics of goats in relation to heat tolerance in the hot tropics. Small Ruminant. Res., 18: 245-248.

Cena, K. and Monteith, J.L. 1975a. Transfer processes in animal coats. I. Radiative transfer. Proc. R. Soc. Lond. B., 188: 377-393.

Cena, K. and Monteith, J.L. 1975b. Transfer processes in animal coats. II. Conduction and convection. Proc. R. Soc. Lond B., 188: 395411.

Cena, K. and Monteith, J.L. 1975c. Transfer processes in animal coats. III. Water vapour diffusion. Proc. R. Soc. Lond. B., 188: 413-423.

Lee, D.H.K. 1953. Manual of field studies on heat tolerance of domestic animals. FAO. Roma. 161 pp.

Maia, A.S.C., Silva, R.G. e Bertipaglia, E.C.A. 2003. Características do pelame de vacas Holandesas em ambiente tropical: Um estudo genético e adaptativo. Rev. Bras. Zootecn., 32: 843-853. maior proteção à nocividade da radiação solar (Silva et al., 2003).

A interação entre local e raça para as características morfológicas espessura e ângulo de inclinação dos pêlos (tabela III), corrobora com a hipótese de que os animais de Viçosa empregam esse comportamento aumentar o isolamento térmico e facilitar as trocas convectivas e evaporativas, sendo a raça Saanen com o maior ângulo de inclinação, talvez pelo maior número de pêlos, tabela II.

\section{CONCLUSÃO}

Os animais da raça Saanen apresentaram um pelame mais denso, curto e grosso que os animais da raça Pardo Alpina.

\section{AGRADECIMENTOS}

Ao Sérgio Mahfuz, proprietário do Capril Rio Preto e ao Prof. Dr. Marcelo Teixeira Rodrigues, da UFV pelo apoio ao concederem os animais para a realização do trabalho.

Maia, A.S.C., Silva, R.G. and Bertipaglia, E.C.A. 2005. Environmental and genetic variation of the effective radiative properties of the coat of Holstein cows under tropical conditions. Livest. Prod. Sci., 92: 307-315.

SAS Institute. 1998. SAS/STAT. User's Guide: Statistics. Ver. 6.12. $4^{\text {th }}$ ed. Cary. 842 pp.

Silva, R.G. 2000. Introdução à Bioclimatologia Animal. Nobel/FAPESP. São Paulo. 286 pp.

Silva, R.G., Lascala Junior, N. e Pocay, P.L.B. 2001. Transmissão de radiação ultravioleta através do pelame e da epiderme de bovinos. Rev. Bras. Zootecn., 30: 1939-1947.

Silva, R.G., Lascala Junior, N. and Tonhati, H. 2003. Radiative properties of the body surface of cattle and other animals. T. ASAE, 46: 913918.

Udo, H.M.J. 1978. Hair coat characteristics in Friesian heifers in the Netherlands and Kenya. H. Veenman e Zonen, B.V. (Eds.). Meded. Landbouwhugeschool. Wageningen. 135 pp.

Archivos de zootecnia vol. 59, núm. 228, p. 612. 